Humour and laughter in meetings: influence, decision-making and the emergence of leadership

To appear in: Discourse and Communication

Date accepted: 24 October 2016

Cate Watson*

Valerie Drew

Faculty of Social Sciences

University of Stirling

Stirling FK9 4LA

UK

*Corresponding author: cate.watson@stir.ac.uk 


\section{Humour and laughter in meetings: influence, decision-making and the emergence of}

leadership

\section{Abstract}

Recent constructions view leadership as a process of social influence which coordinates processes of change. Moreover, such processes are not necessarily linked to role hierarchy but may be emergent and distributed within teams. However, the micro-processes through which this occurs are not well understood. The significance of the paper lies in its contribution to an understanding of the emergence of leadership in teams, and in particular how humour and laughter are drawn on as a resource by which to exert social influence. Here, we use the construct of the play frame, 'non serious' talk in which participants jointly construct extended humorous sequences as improvisations, to analyse how team members manoeuvre in order to accomplish influence, decision-making and leadership. In taking this approach we are not concerned with considerations of how managers use jokes to exercise control, or workers use humour to subvert management. Rather, we examine how humour, and particularly the laughter it engenders, can contribute to an understanding of organizations as centred on communication and founded on the precept that organizations are 'talked into being'. Here we show how talk in a play frame institutes a context which can be utilised by participants to exert influence and we demonstrate the highly contingent and contextual nature of the emergence of leadership within teams.

\section{Key words}

Communicative constitution of organization (CCO), humorous discourse, play frame, relational leadership, strategic accomplishment 


\section{Introduction}

Holmes and Marra (2006:121) suggest that 'strictly speaking' humour is redundant in the workplace and so, they ask, given its ubiquity 'it is always worth asking why it occurs'. Humour undoubtedly contributes to the culture of the workplace and a number of functions have been attributed to it, among them to 'create team' and develop bonds of collegiality (Holmes and Marra, 2006; Kangasharju and Nikko, 2009; Marra et al, 2016); promote the formation of group identity (Romero and Pescosolido, 2008); facilitate communication (Wood et al, 2011); stimulate creativity (Holmes, 2007); and maintain positive work relations (Holmes and Marra, 2002). As such, humour is certainly relevant to practices of leadership and management. Kangasharju and Nikko (2009), for example, claim that humour can be used strategically by leaders and managers to enhance collegiality and improve team effectiveness. Indeed some companies (including Ben and Jerry's, Kodak and Southwest Airlines) have invested heavily in creating working environments in which employees have a duty to have 'fun' (Romero and Cruthirds, 2006; Warren and Fineman, 2007). As well as fostering positive and creative work cultures Holmes and Marra (2006) found evidence that humour may be used by managers to exercise control, using humour to mitigate potentially face threatening acts, thereby softening and making more acceptable a reprimand. Thus, Holmes and Marra maintain, humour may serve to 'do' power and politeness (often simultaneously) and they provide examples of both, showing how 'workplace leaders make use of humour as a sophisticated strategy for constructing their leadership identity while helping achieve their organization's objectives' (Holmes and Marra, 2006:122, emphasis added). 
While the literature on humour in the workplace emphasises its positive aspects - indeed, Romero and Cruthirds (2006:59; emphasis original) define 'humor' as 'Amusing communications that produce positive emotions and cognitions in the individual, group, or organization' - it is worth remembering that not all humour has such benign intent. Humour (and certainly the laughter it engenders) can also be used be used by managers to discipline workers or by workers to subvert or resist directives from management (Parker et al., 2007). Humour is thus a much more ambiguous construct than much of this literature suggests, entering into both the maintenance and contestation of social order (Watson, 2015). This range of functions suggests that far from being redundant, humour and laughter are inescapable elements of workplace culture and relations. Indeed, as Plester (2015) demonstrates, attempts by cheerless bosses to banish workplace humour may be counterproductive. Yet, humour and laughter are often dismissed as barely worthy of serious consideration (Watson 2015) and their role in processes and practices of leadership and management is frequently downplayed.

However, even those studies which do recognise the importance of humour and laughter to leadership and management tend to be based on the assumption that leadership is a function of the 'charismatic leader' who uses humour to 'positively impact the group' (Romero and Pescosolido, 2008:401). Holmes and Marra (2006:123) also regard humour as a 'valuable strategic resource... which leaders can choose to use where appropriate'. Thus, humour is widely seen as a tool for leaders and managers to achieve certain desired outcomes. Romero and Cruthirds (2006) go so far as to suggest that there is 'a science to humor' which can be applied by managers and leaders within organizations, and that such skills can be taught via 'humor-training seminars' (they are not joking). However, this view 
of leadership as an 'entity based' attribute which assumes individual agency has been challenged by complexity-based theories which refuse to define leadership as solely within the purview of the individual. Uhl-Bien (2006:655) defines leadership as a relational process of

social influence...through which emergent coordination (i.e., evolving social order) and change (e.g., new values, attitudes, approaches, behaviors, and ideologies) are constructed and produced... This perspective does not restrict leadership to hierarchical positions or roles. Instead it views leadership as occurring in relational dynamics throughout the organization.

It is perhaps surprising then that so little attention has been paid to humour and laughter in relation to the social emergence of leadership in teams. This is especially so when one considers that much humour in the workplace is 'jointly and dynamically constructed by interlocutors in context' (Rogerson-Revell, 2007:8) and hence would be expected to have a significant impact on these processes of negotiation.

The aim of this paper then is to go beyond an examination of the functions of humour and laughter in the workplace. Instead, we focus on what humour and laughter enable participants to do, in interactional terms, in relation to influence, decision-making and the emergence of leadership. In this way the paper draws on and contributes to the understanding of organizations as centred on communication and founded on the precept that organizations are 'talked into being' (Boden, 1994). Within this overarching (though undeniably heterogenous) theoretical framework, communication becomes not merely a means by which organizations set about the business of organizing themselves, rather 
organization is a dynamic process of communication. Indeed, Cooren et al (2011: 1150;

original emphasis) contend that

organizations can no longer seen as objects, entities or 'social facts' inside of which communication occurs. Organizations are portrayed, instead, as ongoing and precarious accomplishments realized, experienced, and identified primarily - if not exclusively - in communication processes.

In this way, drawing on Giddens, Boden (1994: 11) argues that the day-to-day production and reproduction of social entities 'is accomplished through the essential recursiveness of social life as constituted in social practice' and located in the 'turn by turn moment to moment development of social life'. Thus, it is in the local and contextual interactions of participants that organizations are performatively enacted. In this paper we examine how humour and laughter, as forms of communication, contribute to this theorisation of organization.

Fundamental to the 'communicative constitution of organization' (CCO) (Cooren et al, 2011) are meetings: arguably the essential matter of organizations, and 'one of the main arenas where organizational knowledge and culture are created, negotiated and disseminated' (Svennevig, 2012,p.3). Meetings are where the social production and reproduction of organizations occurs. As such, meetings are very particular kinds of places for talk, usually with a designated chair overseeing proceedings, well-understood rules governing turntaking, topics for discussion decided in advance, and a specified timeframe for completion (if you're lucky). Clearly, the characteristics of meetings vary enormously from very formal affairs concerned with high level institutional governance to less formal team meetings but 
the fundamentals are set out in the following definition (though some might question the requirement for a minimum of three participants):

A communicative event involving three or more people who agree to assemble for a purpose ostensibly related to the functioning of an organization or a group, for example, to exchange ideas or opinions, to solve a problem, to make a decision or negotiate an agreement, to develop policy and procedures, to formulate recommendations, and so forth. A meeting is characterized by multiparty talk that is episodic in nature, and participants either develop or use specific conventions . . . for regulating this talk. (Schwartzman, 1989:7; quoted in Svennevig, 2012:4)

Meetings thus differ from other less formal group encounters in the workplace, of the 'water cooler' variety. Though widely recognised as important places for the sharing of organizational knowledge (Fayard and Weeks, 2007), such encounters are not the focus of this paper.

While it is undoubtedly true that many decisions are taken away from the formal business of meetings, nevertheless, as Marra (2007: 144) suggests, 'reaching decisions is one of the primary goals' of meetings. Huisman (2001:83) defines a decision as a 'commitment to future action', understood as a more or less tangible outcome of the meeting. However, analysis of transcripts of meetings indicates that the emergence of a decision is a far less final business than this might suggest. Huisman's work demonstrates that it is not always easy to identify the precise moment when a decision has been made (this can only be determined in retrospect). Moreover, an apparent decision can prove to be provisional and 
may be undone by subsequent moves. Decisions are thus subjective, contingent and interpretive (Huisman, 2001). Moreover, Clifton (2009) distinguishes between decisionmaking and decision-announcing. While the latter may be the prerogative of the chair, the former is 'an action in which all the team members are accountably able to participate' (Clifton, 2009: 61).This is the quality of decision-making that links it to influence and hence leadership understood as an emergent and distributed property (Gronn, 2009), and it is this that is our central concern.

The remainder of this paper is structured as follows. We first of all define humour and laughter and how we have drawn on these constructs in the present study. We then set out the case examined, a series of interorganizational meetings in which we were participants, and present three examples of humour/laughter each of which do leadership in different ways. We conclude with a discussion of the findings and the implications of these for understanding the emergent and contingent nature of leadership as unfolding in the turnby-turn interaction of participants.

\section{Humour, laughter and the 'play frame'}

The study of humour and laughter is beset with a number of difficulties including: how humour is defined; the relationship between humour and laughter; and the difficulties of deciding between the speaker's intent and the hearer's reception of a 'humorous' remark. In line with many contemporary scholars we understand humour to be 'an umbrella term' to cover all categories of the funny 'including wit, satire and jokes' (Lippit, 1994:147), but we extend it to cover those familiar instances in conversations where participants conjointly 
construct extended humorous sequences as improvisations (Holmes et al, 2007). In relation to the second point, while it is a commonplace to observe that humour is often accompanied by laughter, and laughter can be a signal that something communicated has been found humorous, it is certainly not the case that all instances of laughter are produced in response to humour. Nor is it always the case that what is intended to be humorous elicits laughter as a response (as we know to our cost), while on occasion, non-humorous remarks can be received as highly amusing (ditto). In this paper we are concerned with sequences of talk-in-interaction that occurred in formal meetings, were understood as humorous by participants, and in which laughter was a central feature.

Here we make use of the concept of the 'play frame' (Coates, 2007). Drawing on the work of Gregory Bateson around psychological 'frames', Coates argues that conversational participants 'can frame their talk as humorous by signalling "This is play"' (Coates, 2007:31):

The notion of a 'play frame' captures an essential feature of humour - that it is not serious - and at the same time avoids being specific about the kinds of talk that can occur in a play frame: potentially anything can be funny.

Talk in a play frame can be understood in relation to Mulkay's (1988) distinction between humorous and serious discourse. Mulkay characterizes serious discourse as 'unitary'. Serious discourse attempts to provide rational explanations for the 'reality disjunctures' which present themselves so often to experience. Humorous discourse, by contrast, is characterized by ambivalence and is accepting of the ambiguities, contradictions and paradoxes latent in social constructions of reality (Watson, 2015). 
Talk in a play frame is qualitatively different from 'serious talk' in that it involves collaborative co-construction, or what Coates describes as 'all-in-together talk' which, she suggests, promotes intimacy between speakers (see also Jefferson et al, 1987). This all-intogetherness is characterized by five main linguistic and para-linguistic features of talk: overlapping speech, the co-construction of utterances, repetition, laughter, and metaphor which are often co-present in a given section of talk. In the context of meetings, Coates suggests, it is the 'all-in-together' nature of the play frame that promotes solidarity within the team, for example, diffusing tensions or 'to provide light relief from a boring agenda' (Coates, 2007:33). However, while fully accepting this aspect of talk in a play frame, in this paper we go further, showing how such talk, even though regarded as 'non serious' by participants, can nonetheless serve to accomplish other strategically important ends.

In this paper we analyse a series of meetings which took place as a result of a Scottish Government-mandated partnership between a university and four local authorities established with the aim of furthering the policy desire for teachers to engage in masters level career-long professional learning. A high level strategy group (replete with the signing of concordats) was formed to steer the partnership and as a result of this a working group (WG) was set up charged with developing a model of work-based professional learning which would more closely involve local authorities in the design and delivery of awardbearing masters level professional learning. The WG comprised four University staff (two of whom are the authors of this paper) who were an established team working in professional education; four Local Authority (LA) staff (two headteachers, one classroom teacher, and one senior official), representing the four partner local authorities; and two research assistants who were full-time doctoral students at the University. The type of partnership 
can therefore be characterized as an 'interorganizational collaboration' defined by Hardy et al (2005:58) as a 'relationship in which participants rely on neither market nor hierarchical mechanisms of control to gain cooperation from each other' (Watson and Drew, 2016). The case is particularly interesting for examining the emergence of leadership in meetings since, although the WG appointed a chair (the first author, and PI of the research project), there was no formal management hierarchy. This is not to say, of course, that there were no asymmetries of power arising from status and prior-established relationships. Thus, the four University staff were already an established team developing and delivering masters-level courses for teachers. The four LA staff were not known to each other prior to the establishment of the WG, although two were known to the University members. The doctoral students appointed as research assistants felt that their role was not to participate in discussions, but to undertake tasks designated to them by the group. For the most part they listened unless expressly invited to contribute. The heterogeneous nature of the group, combined with its specific remit, provided considerable scope for the negotiation and emergence of leadership. The WG met for four half-day meetings over a six-month period (three times in the University and once in the school of the headteacher). All these meetings were audio-recorded and form the basis of the analysis presented here.

The paper presents three examples of talk in a play frame that occurred during these meetings. These were at the end of Meeting 1 ('Muffin chat'); during a coffee break and the resumption of business in Meeting 3 ('Toronto Tower'); and during the 'business' part of Meeting 4 ('Cycling chat'). They have been selected from the many humorous interchanges that occurred throughout the interorganizational partnership as capable of three very distinct interpretations each with a significant bearing on leadership, influence and decision- 
making in meetings. Through these three examples we provide insights into the processes of decision-making and the emergence of leadership.

(Transcription: $U$ indicates University member of staff, followed by a distinguishing initial; $L$ is a Local Authority member. Transcription conventions are given in Appendix 1. All participants were female apart from LT.)

\section{Analysis of data}

\section{Example 1. Muffin chat (Meeting 1)}

(Ending the meeting)

This first excerpt concerns events that occurred at the close of the first meeting and WG members were preparing to leave. During the meeting introductions had been effected and the parameters of the task had been set out (Watson and Drew, 2016).

In this example, a collaborative coda to the meeting is produced which illustrates at one level how humour and laughter can 'create team' but also illustrates how members make contingent use of this to position themselves, drawing on institutional and individual identities. In particular, in this example, one LA member (LS) draws on a jointly produced story line to consolidate her position as a leading player in the team, with the potential to exert influence.

1. UC: great + well thank you all very much indeed + really good

2. [pause and some comments heard - 'thank you'; 'yes' etc]

3. UA: feel free to take a muffin $/($ ) 

4. LL: $/[$ laugh $] \backslash+$
5. LL: you can't get rid of these muffins at all can you? /[laugh]\
6. $\quad$ /[group laughter] \

The meeting ends with UC thanking everyone and offering an evaluative comment (Line 1). This is followed by UA who effectively indicates that people may/should now leave by offering the left over muffins provided with tea/coffee (Line 3). Although UA may have been initiating a 'play frame', drawing on the somewhat comical (not to say mildly risqué) reputation of muffins, it is LL who decisively institutes the play frame by responding to UA's comment with laughter (making reference to an earlier event in the meeting when refreshments had been proffered and the muffins largely rejected) (Line 4). There is a pause and, perhaps since there is no accompanying laughter, she follows this up with what amounts to an explanation for the laughter, followed by another laugh (Line 5) which is treated as an invitation to laugh by other members of the WG (Line 6)(Glenn, 2003). The acceptance of this invitation ratifies the play frame. In this brief exchange participants deftly and economically enact their distinctive institutional identities. AU takes membership categorisation 'host' and as such addresses only local authority members of the working group.

The exchange goes on:

7. UM: they weren't as nice as they looked

8. LL: /you're not selling them [laughs]\}

9. UC: /they didn't even look that good \

10. LS: I think muffins never are actually ++ there's something about a muffin + 
11. LL: /[laugh] $]$

12. UA: /[laugh]\

13. LS: a muffin's never really a fairy cake is it? + it might aspire to / be a fairy cakel 14. /[general laughter]\

In this extract UM offers an evaluative comment about university catering (Line 7) to which LL responds and laughs (Line 8). Following this, LS introduces the humorous idea that muffins never are as nice as they look, and can only aspire to be fairy cakes (Lines 10 and 13). UA and LL laugh. Following $L S^{\prime}$ 's evaluation of muffins there is overlapping speech from UA and LL.

15. UA: LS that could /be the

16. LL: /there's a \philosophy behind that

17. UA: LS that could be the title of your first novel

18. LS: absolutely

19. UA: A muffin is never really a fairy cake [said as if a book title] $(\ldots)$

20. LL: [laughs] it' $d$ be a good title for a book LL and AU offer appreciation of LS's remark (Lines 15-17). LS accepts this decisively (Line 18) and UA repeats this as if it is the title of a book (Line 19). LS then continues:

21. LS: $\quad$ or if you want some personal baggage +

22. LS: my sister was a fairy cake but I was always a muffin [exaggerated high voice] 
23. $/[$ overlapping raucous laughter] $/$

24. UA: /now we've got that on tapel

25. [laughter starts to subside]

This personal revelation, which makes use of the muffin metaphor (Lines 21,22 ), brings the house down. Here the ambiguity within the metaphor is evident - is LS contrasting herself as assertive, and independent minded, with her sister as a compliant goody two shoes (in which case the WG has been warned), or is she perhaps suggesting that her sister was favoured over her (with guessed at psychological consequences)? There might also be sexual overtones in relation to a hinted at naughtiness. These ambiguities are left to resonate.

The play frame switches the talk from serious to humorous discourse in which ambiguity and multiplicity are evident, highlighting the gap between what is said and what is meant (this exchange has nothing to do with muffins). However, while the overall effect is of disorderliness, with violations of the normal conversational rules associated with a 'one-ata-time' floor (Coates, 2007:39), this disorderliness hides some very orderly talk. In particular, in the midst of the overlapping talk and laughter LS is allowed to speak without interruption, despite her pauses (Lines 10,13) and it is this assertiveness that establishes her position as significant within the group.

The contingent nature of the exchange is evident in the turn by turn unfolding with LS skilfully using the play frame to position herself as an influential player, taking advantage of the non-serious talk to exercise influence without appearing to do so overtly. LS draws on 
the play frame to consolidate the position she had started to establish during the meeting, thereby securing future influence within the WG.

\section{Example 2. Toronto Tower (Meeting 3)}

(Resumption of meeting after coffee break)

The tape had been switched off during the coffee break. Just prior to the resumption of the meeting the tape was switched on again. Laughter is heard. Talk at coffee had been about an abseiling window cleaner who unexpectedly appeared at the window and this extract follows on from that occurrence. In this extract, it is not the conversation itself that is of relevance to the emergence of leadership. Rather, the focus is on what the play frame enables UV to achieve in terms of asserting her leadership within the context of the WG task. Jefferson et al (1987: 159) refer to this form of laughing together as an 'accessory activity ... performed as a way to arrive at some specifiable outcome [and] has a significant bearing on a, or some next actions' and this is certainly the case in this example.

After some preliminary comments, the context for which is now lost, LL tells a story about the 'Edgewalk' ${ }^{1}$ at the Toronto $\mathrm{CN}$ Tower and the regulations covering this.

1. LL: see when you go up the Toronto Tower +

2. LL: they have a list of things they have to remove +

3. LL: you know + earrings +

4. LL: and there's a whole list of things you can't take with you

5. LL: in case + obviously + it drops off the roof 
6. LL: and one of them is swords

7. ?: swords?

8. $\quad /[$ general laughter $] \backslash$

9. LT: /( )dangerous if you drop your sword [laughs] $\backslash$

10. /[general laughter] $\backslash$

11. UA: oh dear [said with a sigh]

12. UM: so you chose to not do it and retain your sword

13. LL: $\quad$ I + I just thought $+y^{\prime}$ know + I need ma sword

14. LL: that was the excuse for not putting myself through /fear of death\}

15. / / /general laughter]

16. UV: I know

17. [laughter subsides rapidly]

18. [long pause of 2 seconds]

19. UV: Cate [said very distinct and clipped]

20. [some group laughter]

This section of talk is characteristic of humour sequences in meetings: 'overlapping speech in a collaborative floor [which] entails a richer multi-layered texture to talk where speakers demonstrate their shared perspective' and their attunement to one another' (Coates, 2007: 39). There is co-construction of the humour with LL and UM collaborating in a fantasy sequence (Lines 12 and 13]. This exchange, between a university and a local authority member of the group, is indicative of the closeness of the collaboration at this stage of the 
project, the third meeting. Holmes and Stubbe (2003) found that extended sequences of humour are more likely among women than men, and they suggest that such sequences 'tended to generate good feeling and positive collegial attitudes' (p.578). While this may be true, in the context here it can be seen that this exchange provides an opportunity for UV to exercise leadership as strategic influence in what follows.

Video would undoubtedly have assisted in the analysis of this move from break to resumption of the meeting, instead we rely on notes and recall based on habitual practices of the chair (Watson) in similar situations. The laughter has subsided rapidly, we have all now sat again at the table ready to resume the (serious) business of the meeting, normally signalled by Watson through a change in posture (to more upright), looking down and paying attention to the agenda or other document, a pause to allow the group to compose themselves, followed by a 'boundary marker' (Boden, 1994) such as 'OK, so'. In this instance, there is a long pause of 2 seconds (Line 18) (which in ordinary conversation might signal 'trouble', but in the context of opening business meetings has been noted by others, for example, Nielsen, 2009) and then UV, in a mock officious tone directs the chair to resume the meeting (Line 19). In this way UV makes use of and extends the play frame established during the coffee break and uses this to establish herself in a position of authority with respect to the chair. Within the context of the play frame this can be claimed to be 'joking' but it introduces ambiguity in that UV has constructed herself as group 'leader'. This is an example of what Boden (1994:18) refers to as 'turn making' (as distinct from turn taking) 'as actors use talk environments to advance or subvert the main policies and political moves of the organizational day'. Asserting this leadership role arguably legitimises a subsequent long turn UV takes in which she is influential in the outcome of a 
decision that the WG had previously constructed as crucial in relation to the task being undertaken. This key decision concerned the nature of the support to be provided to teachers by the local authority while they undertook their work-based learning in school. In particular, the naming of this in-school support had come to be regarded as pivotal by the WG. The single utterance 'Cate' (and what it subsequently enables UV to achieve), points to the highly contingent and contextual nature of influence and leadership in meetings.

Following UV's instruction to resume, UC then outlines the focus for the next stage of the meeting. This is spoken with a good deal of hesitation and reference to 'the transcript', the audio-recording of the previous WG meeting, which serves as a record and authoritative source. Reference to this represents an appeal to prior collective decisions of the group and legitimizes this talk. It also reinforces the identity role of the chair as a facilitator of the meeting rather than a manager as is also attested to by the repetition of 'perhaps'.

[part of transcript deleted[

21. UC: $\quad$ and + then thinking about the purpose of support +

22. UC: and the naming of the supporter +

23. UC: $\quad$ so those are + perhaps areas we need to + perhaps

24. UC: um discuss + and flesh out now

Following on from this, there is a pause of one second before UV says:

25. UV: um + can I um start again? [laugh] 
26. UC: $\quad m m$ please do $+\operatorname{Dr}$ [name]

UV assumes the floor (Line 25), asserting her right to do so, but couching this as a request to the chair, and at the same time softening this with a humorously self-deprecating reference to the fact that she is well known to talk a lot. UC assents and then pauses briefly before adding the mock formal address (Line 26), orienting to UV's humorous, though strategically important claim to the right to speak. UV then takes a very long and uninterrupted turn (3 minutes 42 seconds) during which she outlines her thinking around the naming of the inschool supporter. Sacks et al (1974:711) comment that, 'Within the small group the time taken by a given member in a given session is practically a direct index of the amount of power he has attempted to exercise in that period'. Thus, UV's 'turn making', in asserting her right to speak, at this point is very relevant. This turn (not shown in the transcript) culminates with UV suggesting the name 'Critical Colleague' and the chair announces the decision 'think you've cracked it there', which is assented to by all. Thus, there has been a swift exit from what might be characterised as a 'mini' play frame (Lines 25 and 26), with UV having used this to exert influence in relation to the strategically important decision around the naming of in-school support. Thus, the play frame, instituted in the coffee break, is taken advantage of by UV and used to do power politely, enabling UV to assume authority and leadership without seeming to do so overtly.

\section{Example 3. Cycling chat (Meeting 4)}

(Humorous sequence during the meeting) 
While the first two examples occurred in parts of the meeting understood as outside of formal business, this final example focuses on a humorous sequence that occurred within the business part of the meeting. A very different function is performed by, what on the surface at least, appears to be a humorous digression during the business of the final meeting. This followed quite a heated discussion about the role of the university tutor during the work-based module. The matter is left unresolved as UM diverts the discussion to include issues around assessment of learning and talks about the work she has been doing with LT on assessment of work-based learning. LT is not present at the meeting and UM is describing his interest in the use of 'run charts' as a means of recording small, continuous improvements to practice. There is quite a long discussion of this, as no one seems very clear about what it is exactly. UM tries to explain, emphasising the very small changes to practice involved. At this point UA makes a reference to the manager of the British Olympic cycle team whose outstanding success he put down to 'the aggregation of marginal gains', meaning that small improvements could collectively add up to a significant improvement in performance.

1. UA: Do you know what that also links to?

2. UA: The em remember there was all that em publicity around the em

3. UA: the GB cycling team's eh + success in the Olympics?

4. UA: and their trainer does something like that which it's it's it's

5. UA: /the minimal aggregation -

6. UC: /it's the aggregation of<smiles>[AlH2]</smiles> 
UA may be making a serious point here (Lines 1-5) but UC, orienting to an identity as cyclist and keen follower of the Tour de France, interjects (Line 6) (though she cannot recall the exact phrase either) and institutes a play frame, introducing the potentially risky idea that this improvement might in fact be due to other causes (given the reputation of international cycling) which draws forth considerable laughter (section of transcript deleted). UA, now fully in the play frame, continues:

7. UA: right down to the change in the kind of chamois in um um

8. UA: the shorts + Chris's knickers [presumably a reference to GB cyclist Chris Froome]

9. UM: really?

10. UA: these tight $+i t^{\prime}$ 's the aggregation of the minimal changes /or something

11. UC: /something like that \

12. ?: /yes yes।

13. UA: /it's it's huh and that's why

14. UA: nothing to do with steroids

15. UV: so let's make it quite clear

16. UV: we are not casting any aspersions

17. UV: against the British cycling team 
18. /[general laughter] $/$

19. UA: no + although we do question the (size of their thighs)

20. UV: [laughs] 'cos I was once on a cycle in the gym

21. UV: and mine ha' never looked like that

22. [general very loud laughter]

23. UA: ( ) [laughs] any way + sorry + right [through laughter]

24. [laughter subsides]

25. [long pause of 3 seconds]

The laughter increases to a crescendo (Line 22) as the talk becomes ever more risqué before subsiding (Line 24). There is a long pause of 3 seconds (Line 25) accompanied by sounds of shuffling of paper.

26. UM: So I don't have anything else to add to assessment

27. UC: So we're happy to go with what we've discussed today and what's been outlined.

The play frame is very decisively exited with UM's comment (Line 26) and UC underlines this with a decision-announcement (Line 27) based on what 'we' have decided - though what has been decided, if anything, is far from clear (this points up the 'bounded rationality' of decision-making (March, cited in Boden, 1994)). It has been proposed that the interjection of humour often follows a 'difficult or complex discussion' (Holmes and Marra, 2006:109). This is certainly the case here where the humorous sequence follows a 
discussion of the deeply contested role of the tutors in the work-based module. So, entering this playful digression functions to ease the tension, re-establishing collegiality. However, another interpretation is possible. In effect, the sequence in the play frame serves to interrupt the discussion. When serious business is resumed the chair does not make reference to the previous discussion but instead announces a decision. The play frame, initiated by the chair, can thus be seen in this context as satisfactorily closing a contested discussion and this allows the chair to assert leadership through the announcing of a decision (though it may only be provisional, postponing renewed discussion, see Huisman, 2001). This is a pattern of events for which we have collected several examples in different contexts and is an aspect of talk in a play frame which deserves exploration in greater depth.

However, 'cycling chat' is also rather ambiguous and its content could be interpreted as a critical commentary (as derision) of the approach to school improvement advocated by LT. Thus, the sequence is used to 'do power' in the group covertly. It highlights a suppressed tension in the WG between the university and local authorities in which the university WG members invoke an academic identity, through the familiar ploy of positioning oneself in relation to the 'other' who is generally to be found wanting (Watson, 2012). Thus, the fault lines in interorganizational collaboration are never far from the surface (Watson and Drew, 2016).

\section{Conclusion}

The three examples provided here illustrate different ways in which the WG members drew on shared laughter to interactionally accomplish particular strategic ends. In the first 
example, at the close of the first meeting of the WG, the talk and laughter in the play frame is certainly used to 'create team' (Holmes and Marra, 2006) but this apparent move to promote bonding within the group masks some very individual and collective positioning which concerns identity. The opening of this sequence around the offering of muffins neatly enacts the organizational identities of the two groups, while LS uses talk in a play frame to position herself as an influential player within the group. In the second example, UV is able to use the play frame as cover to exert leadership within the group, through directing the chair to resume the meeting, thereby illustrating the highly contingent and contextual nature of influence and the emergence of leadership. In the third example, the chair engineers a play frame as a means to interrupt a highly contested issue at the close of which a collectively arrived at 'decision' is announced. In each case the production of laughter recruited others in the group into the play frame, providing the ambiguity and 'cover' needed to exert influence and assume leadership. The common thread in the three examples is the strategic use of the play frame to assert leadership as an aspect of influence within 'team' in a way which is not damaging to the enterprise. Thus, it seems that rather than laughter being a mere product or response to humour, it may be that in this context the principal function of humour is to draw forth shared laughter which then serves to align the group within the play frame, orientating the group to humorous discourse with its acceptance of ambiguities and apparent irrationalities. Laughter is not thus an adjunct to humour, a mere side product, but a linguistic imperative. Jefferson et al (1978:170) comment that 'laughter is a methodically produced activity, which can itself be a component of a methodically produced sequence of activities: i.e. it is socially organised in its own fine-grained particulars, and at a grosser level as well'. Within the play frame the 'normal' rules of interaction are suspended. The floor is open to all to use strategically. Once 
entered, influence, decision-making and leadership can be accomplished in particular ways, doing power without seeming to do so. The play frame legitimises a 'breakdown' of the usual rules for turn taking but actually occasions a context in which 'different' interactional achievements are accomplished and which can be drawn on by participants to achieve objectives regarding influence, decision-making and leadership. They may thus be able to achieve strategic ends that would be unable (or perhaps more unacceptable) to achieve in other ways within the serious discourse of the meeting. There may be a gendered aspect to this since the WG was overwhelmingly female. As Coates (2007) observes, male humour is more centred around the telling of jokes, while females' laughter 'emerges as the result of humorous stories, or of bantering or teasing among participants, or when speakers pick up a point and play with it creatively' (p.31). Arguably, the masking of power is associated with feminine ways of accomplishing ends (see also Holmes and Stubbe, 2003). Thus, politeness, and the need to pay attention to the 'collective face wants' of the group may be an important aspect of this kind of interaction (Watson et al, 2016).

In none of the examples is the content of the play frame material to the enterprise. It is the fact of engaging in humorous discourse that provides the opportunity to exert influence and exercise leadership. In doing this the participants demonstrate neat and economical ways of achieving very sophisticated ends. The analysis here presented here draws attention to the strategic nature of talk as an interactional accomplishment, and to answer the question 'why that now?' (Schegloff et al, 2002:5). However, Schegloff et al, while recognising that talk in an institutional context does 'go off task' (p.11), do not subject this to analysis. In this paper we have advanced a theory to account for these 'transgressions'. The paper thus makes a contribution to the understanding of organizations as centred on communication 
and the highly contingent, contextual and local way in which this is achieved. What we have advanced is very preliminary at this stage, but does point the way to further analysis of the role of humorous discourse in the accomplishment of very serious strategic ends.

\section{Note}

${ }^{1}$ http://www.edgewalkcntower.ca/

\section{References}

Boden, D. (1994). The business of talk: Organizations in action. Cambridge: Polity Press.

Clifton, J. (2009). Beyond taxonomies of influence: "Doing" influence and making decisions in management team meetings. Journal of Business Communication, 46(1): 57-79.

Coates, J. (2007). Talk in a play frame: More on laughter and intimacy. Journal of Pragmatics, 39(1): 29-49.

Cooren, F., Kuhn, T., Cornelissen, J. P., and Clark, T. (2011). Introduction to the special issue: Communication, organizing and organization: An overview. Organization Studies, 32: $1149-1170$.

Fayard, A., and Weeks, J. (2007). Photocopiers and water-coolers: The affordances of informal interaction. Organization Studies, 28(5): 605-634.

Psathas, G. (1995). Conversation analysis: The study of talk-in-interaction. London: Sage. 
Gronn: (2009). From distributed to hybrid leadership practice. In A. Harris (Ed.), Distributed leadership (pp. 197-217). Dordrecht: Springer.

Hardy, C., Lawrence, T. B., and Grant, D. (2005). Discourse and collaboration: The role of conversations and collective identity. Academy of Management Review, 30(1): 58-77.

Holmes, J. (2007). Making humour work: Creativity on the job. Applied Linguistics, 28(4): 518-537.

Holmes, J., and Marra, M. (2002). Over the edge? Subversive humor between colleagues and friends. Humor, 15(1): 65-88.

Holmes, J., and Marra, M. (2006). Humor and leadership style. International Journal of Humor Research, 19(2): 119-138.

Holmes, J., and Stubbe, M. (2003). Feminine workplaces: Stereotype and reality. In J. Holmes, and M. Meyerhoff (Eds.), The handbook of language and gender (pp. 573-599). Oxford: Blackwell.

Holmes, J., Schnurr, S., and Marra, M. (2007). Leadership and communication: discursive evidence of a workplace culture change. Discourse and Comunication 1(4): 433-451.

Huisman, M. (2001). Decision-making in meetings as talk-in-interaction. International Studies of Management and Organization, 31(3): 69-90.

Jefferson, G., Sacks, H., and Schegloff, E. (1987). Notes on laughter in the pursuit of intimacy. In G. Button, and J. Lee (Eds.), Talk and social organisation. (pp. 152-205). England: Clevedon. 
Kangasharju, H., and Nikko, T. (2009). Emotions in organizations joint laughter in workplace meetings. Journal of Business Communication, 46(1): 100-119.

Lippitt, J. (1994). Humour and incongruity. Cogito, 8(2): 147-153.

Marra, M. (2007). Huour in workplace meetings. Challenging hierarchies. In, R. Westwood and C. Rhodes, (Eds) Humour, work and organization, (pp.139-157). London and New York: Routledge.

Marra, M., Schnurr, S., and Holmes, J. (2016). Effective leadership in New Zealand workplaces. In J. Baxter (Ed.), Speaking out. The female voice in public context. (pp. 240260). Dordrecht: Springer.

Mulkay, M. (1988). On humour. Cambridge: Polity Press.

Nielsen, M. F. (2009). Interpretative management in business meetings. Understanding managers' interactional strategies through conversation analysis. Journal of Business Communication, 46(1): 23-56.

Parker, M., Westwood, R., and Rhodes, C. (2007). The little book of management bollocks and the culture of organization. In R. Westwood, and C. Rhodes (Eds.), Humour, work and organization. (pp. 77-92). London: Routledge.

Plester, B. (2015). The complexity of workplace humour: Laughter, jokers and the dark side of humour. London, New York: Springer International Publishing.

Rogerson-Revell: (2007). Humour in business: A double-edged sword: A study of humour and style shifting in intercultural business meetings. Journal of Pragmatics, 39(1): 4-28. 
Romero, E. J., and Cruthirds, K. W. (2006). The use of humor in the workplace. The Academy of Management Perspectives, 20(2): 58-69.

Romero, E., and Pescosolido, A. (2008). Humor and group effectiveness. Human Relations, 61(3): 395-418.

Sacks, H., Schegloff, E. A., and Jefferson, G. (1974). A simplest systematics for the organization of turn-taking for conversation. Language, 50(4):696-735.

Svennevig, J. (2012). Interaction in workplace meetings. Discourse Studies, 14(1): 3-10.

Uhl-Bien, M. (2006) Relational Leadership Theory: Exploring the social processes of leadership and organizing. The Leadership Quarterly 17 (1): 654-676

Uhl-Bien, M., Marion, R., and McKelvey, B. (2007). Complexity leadership theory: Shifting leadership from the industrial age to the knowledge era. The Leadership Quarterly, 18(4): 298-318.

Warren, S. and Fineman, S. (2007). 'Don't get me wrong, it's fun here, but...' Ambivalence and paradox in a 'fun' work environment. In, R. Westwood and C. Rhodes, (Eds) Humour, work and organization, (pp.92-112) London and New York: Routledge.

Watson, C. (2012). Analysing narratives: The narrative construction of identity. In S. Delamont (Ed.), Handbook of qualitative educational research, (pp. 460-472). Cheltenham: Edward Elgar Publishing.

Watson, C. (2015). Comedy and social science: Towards a methodology of funny. Abingdon: Routledge. 
Watson, C. and Drew, V. (2016) Enacting educational partnership: collective identity, decisionmaking (and the importance of muffin chat) School Leadership and Management http://dx.doi.org/10.1080/13632434.2016.1209181

Watson, C., Wilson, A., Drew, V. \& Thompson, T-L. (2016). Criticality and the exercise of politeness in online spaces for professional learning. Internet and Higher Education 31, 43-51.

Wood, R. E., Beckmann, N., and Pavlakis, F. (2007). Humor in organizations: No laughing matter. In J. Langan-Fox, C. L. Cooper and R. J. Klimoski (Eds.), Research companion to the dysfunctional workplace. Mangement challenges and symptoms. (pp. 216-231). Cheltenham: Edward Elgar Publishing. 


\section{Appendix 1. Transcription notation.}

Absolutely underlining indicates emphasis

[ laughs] square brackets indicate paralinguistic features

+ pause of up to 1 second

/.... simultaneous speech

( ) indistinct. Word in the brackets indicates transcriber's best guess

? rising or questioning intonation

- $\quad$ cut off speech

(...) section of transcript deleted

(Holmes et al, 2007) 